\title{
DIALOGIA E INSIGHT: NARRATIVAS DE PAIS E FILHOS SOBRE O TRANSTORNO DE ASPERGER
}

\author{
DIALOGISMO Y INSIGTH: NARRATIVAS DE PADRES $\Upsilon$ HIJOS SOBRE \\ EL TRASTORNO DE ASPERGER
DIALOGISM AND INSIGHT: PARENTS AND CHILDREN NARRATIVES ABOUT ASPERGER DISORDER

\author{
Carolina Vilar ${ }^{1}$, Amanda Guerra ${ }^{12}$, Jorge Falcão ${ }^{1}$ e Izabel Hazin ${ }^{1}$ \\ ${ }^{1}$ Universidade Federal do Rio Grande do Norte, Natal, RN, Brasil \\ ${ }^{2}$ Université d’Angers, Angers, France
}

\begin{abstract}
RESUMO: O presente estudo objetivou investigar os processos de insight em sujeitos com Transtorno de Asperger (TA). Entende-se por insight o conhecimento do próprio diagnóstico e os sentidos construídos a partir deste. O desenvolvimento do insight é aqui compreendido não como função restrita à vida mental pessoal, mas como fenômeno intersubjetivo, forjado nas relações sociais. O arcabouço teórico que subsidia a presente pesquisa é a perspectiva genética de desenvolvimento avançada pela psicologia histórico-cultural. Para tanto, foram propostas a três díades de pais e adolescentes diagnosticados com TA duas tarefas de produção narrativa que investigaram aspectos relacionados às experiências Asperger. Os resultados sugerem que a característica central dos processos de insight no TA pode ser descrita como disrupção na transição do modo monológico para o modo dialógico de pensamento. Acredita-se que os resultados aqui encontrados contribuem para a compreensão da singularidade e eventicidade da existência e da experiência subjetiva.
\end{abstract}

PALAVRAS-CHAVE: Insight; Asperger; Psicologia Histórico-cultural; Dialogismo.

RESUMEN: El presente estudio tuvo como objetivo investigar los procesos de insight en sujetos con trastorno de Asperger (TA). Insight significa el conocimiento del diagnóstico mismo y los significados construidos a partir de él. El desarrollo del insight se entiende aquí no como una función restringida a la vida mental personal, sino como un fenómeno intersubjetivo, forjado en las relaciones sociales. El marco teórico que sustenta esta investigación es la perspectiva genética del desarrollo que adelanta la psicología histórico-cultural. Para ello, a tres díadas de padres y adolescentes diagnosticados de TA se les ofrecieron dos tareas de producción narrativa que investigaban aspectos relacionados con las experiencias de Asperger. Los resultados sugieren que la característica central de los procesos de insight en TA puede describirse como una interrupción en la transición del modo de pensamiento monológico al dialógico. Se cree que los resultados encontrados aquí contribuyen a la comprensión de la singularidad y la eventualidad de la existencia y la experiencia subjetiva.

PALABRAS CLAVE: Insight; Asperger; Psicología histórico-cultural; Dialogismo.

ABSTRACT: The present article aimed to investigate insight processes in people with Asperger disorder. Insight is understood as the knowledge of one's own diagnosis and the senses built from it. The insight development is understood here not as a function of personal psychological life, but as an intersubjective phenomenon, forged in social relations. The theoretical framework that subsidizes this research is the genetic perspective of development advanced by cultural-historical psychology. For this purpose, two tasks of narrative production were proposed to three dyads of parents and teenagers with $\mathrm{AD}$, which investigated aspects related to Asperger experiences. The results suggest that the central characteristic of insight processes in AD can be described as a disruption in the transition of a thinking monologic mode to a thinking dialogic mode. It is believed that the results here found contribute to the comprehension of singularity and occurrence of subjective experience and existence.

KEYWORDS: Insight, Asperger Disorder; Cultural-historical Psychology; Dialogism. 


\section{Introdução}

No discurso biomédico, o Transtorno de Asperger (TA) é caracterizado por alterações nos domínios da comunicação e interação social, presença de padrões restritos e repetitivos de comportamento, interesses e atividades (OMS, 1996). O TA foi incorporado ao Transtorno do Espectro Autista (TEA) na última versão do Manual Diagnóstico e Estatístico de Transtornos Mentais - DSM-V (APA, 2014). Porém, optou-se aqui pela manutenção do termo, uma vez que se defende que há uma estreita interdependência entre os discursos produzidos e a realidade socioeconômica e cultural de uma época. Sendo assim, não só a palavra impregna e dá sentido à atividade humana ou à experiência social das pessoas, mas igualmente à consciência, que se estrutura a partir da dimensão material do signo, forjado nas trocas comunicativas e sociais de coletivos humanos (Volochinov, 1992).

A importância da definição de TA a partir do discurso biomédico pode ser justificada pelo seu largo em contextos de serviços de saúde, educacionais e clínicos, contribuindo sobremaneira para forjar as identidades subjetivas dos indivíduos diagnosticados, que incorporaram a essa subjetividade os conceitos médicos acerca de si mesmos, construindo sentidos acerca dessa que são atravessados por tal discurso. Porém, para além da definição biomédica, quando se fala das percepções individuais é preciso considerar igualmente as vozes dos pais, da mídia, dos outros representativos. O entendimento sobre "o que é ser Asperger" precisa ir além da consideração dos aspectos nosológicos e nosográficos dessa condição clínica. Assim, torna-se indispensável o esforço de compreensão dos processos de construção de sentidos e significados desses sujeitos acerca de sua condição e do mundo que os cerca. A extensão do entendimento e da avaliação que sujeitos são capazes de ter acerca de uma condição que os afeta tem consequências significativas para as relações estabelecidas entre ele e o mundo social. Pouca consciência de sua condição pode associarse ao não reconhecimento de dificuldades e da necessidade de ajuda. Contraditoriamente, o nível de consciência elevado de uma dada condição clínica também pode estar associado ao aumento de estresse, oriundo da conscientização dos efeitos dessa sobre a sua vida. Logo, pesquisas acerca dos mecanismos inerentes a tal entendimento, em grupos clínicos diversos, são de grande importância para a delimitação de estratégias terapêuticas e da avaliação acerca da eficiência e eficácia das mesmas (Buchman-Wildbaum et al., 2020; Markova \& Berrios, 2011).

O termo insight é mais frequentemente utilizado em estudos referentes à consciência em quadros de transtornos psiquiátricos ou neuropsiquiátricos. Markova e Berrios (2011) propõem uma distinção entre os termos awareness e insight, ambos se referindo ao conhecimento que o indivíduo possui acerca de sua condição e das características dessa, porém, defendem que tais termos não podem ter uso intercambiável. O primeiro se relaciona a aspectos do nível de consciência da doença, de seus sintomas e características. O segundo termo agrega, ao primeiro, dimensões distintas, de caráter subjetivo.

A dimensão do insight envolve a construção de sentidos e significados para uma condição clínica, para os valores sociais dessa, bem como para as experiências de vida a ela associadas. Tal processo de desenvolvimento baseia-se no conhecimento geral (informações midiáticas, de livros e dos pares), experiências passadas (experiências subjetivas em relação a si mesmo e outras pessoas; o grau a que a experiência subjetiva se relaciona ao conhecimento teórico), além de ser atravessado por perspectivas culturais (França et al., 2020; Marková, 2005). 
Nessa perspectiva, defende-se aqui que o fenômeno de insight de Marková (2005) não pode ser considerado como produto individual, mas sim como construção dialógica de sentidos. Partindo-se de uma perspectiva histórico-cultural, o processo de insight pode ser considerado uma função mental superior, uma faceta da consciência de si mesmo construída na interação com os outros e mediada pela linguagem, pelos discursos. Como problematizado por Y. Clot, a consciência não existe enquanto condição apartada, trata-se de uma relação real, a qual só se revela em movimento (Clot, 2014). Nesse sentido, ressaltar a dimensão social do insight implica a consideração das vozes sociais presentes nesse.

Verhoeven et al. (2012) hipotetizaram que indivíduos com TA possuiriam dificuldades em diversas dimensões subjacentes ao conceito de insight, dentre elas destacaram a autorreferência, principalmente quando associada aos déficits de memória autobiográfica. Nesse sentido, indivíduos com Asperger podem ter conhecimento teórico sobre o transtorno, mas não perceber como ele se manifesta em seu dia a dia. Essa falta de consciência, do que chamaram "comportamento de mundo real”, poderia prejudicar a eficácia das intervenções a eles destinadas, pois enquanto os comportamentos atípicos não fossem reconhecidos, existiria menor motivação para buscar ajuda.

Entende-se por atribuição social a percepção pelo indivíduo de seu papel e das outras pessoas em situações sociais. Sendo assim, a atribuição social inadequada poderia combinar-se com dificuldades de insight no Asperger, à medida que problemas ocorridos numa interação social poderiam ser interpretados pelo indivíduo como culpa de outras pessoas envolvidas nessa situação, sem reconhecimento de sua implicação para a mesma. Essa atribuição pode estar associada também a externalizing bias (EB), que diz respeito à atribuição de comportamentos ou dificuldades a fatores externos, com tendência a não reconhecer a própria implicação (Langdon et al., 2006).

O estudo realizado por Didehbani et al. (2012) investigou o insight em indivíduos com Asperger, considerando ainda as variáveis de estilo de atribuição social e EB. Os resultados sugeriram associação entre maior nível de insight e características associadas, com maior tendência a atribuir erros a si mesmo em situações sociais negativas e não aos outros. Em consequência disso, foi percebida diminuição da autoestima.

A investigação de insight também foi abordada sob a ótica da formação da personalidade do indivíduo com Asperger. Schriber, Robins e Solomon (2014) realizaram estudo com o objetivo de investigar o desenvolvimento da personalidade em indivíduos com Asperger e com desenvolvimento típico, bem como mapear se existe variação em termos do insight acerca de sua própria personalidade. Os resultados sugeriram que indivíduos com Asperger apresentam mais traços neuróticos e menos de extroversão, amabilidade, escrupulosidade e abertura para experiências. Em relação ao insight, foram observados níveis equivalentes entre o grupo com Asperger e o grupo controle.

A heterogeneidade dos resultados dos estudos de insight para os indivíduos com Asperger sugere a necessidade de maiores investigações sobre o tema, buscando uma melhor compreensão acerca dos significados e sentidos construídos pelos indivíduos para a sua condição. Isso posto, o presente estudo teve como mote central a investigação dos processos de insight em sujeitos com TA, aqui compreendido não como função de vida mental pessoal, não como uma construção solitária, mas como fenômeno intersubjetivo, forjado nas relações sociais. 


\section{Método}

O arcabouço teórico que subsidia a presente pesquisa é a perspectiva genética de desenvolvimento avançada pela psicologia histórico-cultural. Para N. Veresov (2014) tal perspectiva pode ser sumarizada em quatro pontos: (a) A mudança do foco da pesquisa de estágios de desenvolvimento para processo de desenvolvimento; (b) A mudança do foco das estratégias de pesquisa da investigação do comportamento da criança para a análise do contexto sociocultural e das instituições; (c) A mudança do foco da investigação dos resultados ("frutos") para o processo de transformação dos "botões" em "frutos"; (d) A mudança do foco de "observações clássicas" para observações em condições já existentes ou condições experimentais especialmente construídas.

Isso posto, o foco de investigação é deslocado do produto para os processos de desenvolvimento das funções psicológicas superiores. Este não visa a formular uma lei geral, mas permite generalizações na medida em que a pesquisa transita entre o específico e o geral do desenvolvimento humano, uma vez que o indivíduo tem uma trajetória e história que lhe são peculiares, mas é ao mesmo tempo construído a partir do discursos social sobre determinada patologia, inserido em uma sociedade e um contexto pertencente à espécie humana que compartilham planos de desenvolvimento comuns, a saber, a sociogênese e a filogênese (Vygotski, 2012).

Ressalta-se que compreender o desenvolvimento do fenômeno de insight demanda uma investigação ampla e aprofundada, conforme discutido anteriormente. Dessa forma, os processos de insight serão aqui discutidos a partir da análise de trechos de transcrições discursivas literais produzidas pelos sujeitos e seus pais. Para tanto, foram propostas duas tarefas que investigaram aspectos relacionados às experiências Asperger. Vale salientar que os pais responderam às mesmas tarefas que os filhos, mas estes foram convocados a respondê-las como se fossem seus filhos. A escolha dos respondentes foi realizada pelos sujeitos da pesquisa, a partir do grau de proximidade. Destaca-se que a estrutura dessas atividades e a escolha de conservar as mesmas questões para pais e filhos foram idealizadas com o objetivo de possibilitar aos sujeitos entrar gradativamente em contato com a experiência do TA. Dessa forma, partiu-se inicialmente de conhecimentos mais formais para em seguida abordar experiências individuais, a fim de facilitar o desenvolvimento de insight.

\section{Participantes}

Participaram do estudo três sujeitos do sexo masculino, selecionados por conveniência, com diagnóstico prévio de TA e seus respectivos pais; foi estabelecido como critério de participação o conhecimento deste diagnóstico há pelo menos cinco anos, tempo esse considerado suficiente para a construção de significados e sentidos sobre tal condição. Em função de tais critérios prévios, foram admitidos: Sujeito L. - 20 anos, estudante de graduação em tecnologia da informação; Sujeito $\mathrm{R}-20$ anos, estudante de graduação em engenharia de alimentos e; Sujeito W - 16 anos, estudante do último ano do ensino médio.

As atividades que compuseram o estudo foram realizadas em diferentes locais, de acordo com a disponibilidade dos sujeitos. Pais e filhos responderam às atividades em diferentes ocasiões. Essas foram áudio-gravadas, após autorização destes e seus responsáveis, no caso dos participantes menores de idade. 


\section{Tarefas e Procedimentos}

Foi dada aos sujeitos a seguinte explicação antes da apresentação das atividades:

"Nós pesquisadores estudamos o transtorno de Asperger. Lemos muitas coisas como livros e artigos científicos, mas chegamos à conclusão que pessoas que têm TA são os verdadeiros experts nisso, pois eles podem dizer o que é e como é ter TA. Por isso que procuramos você, para entendermos melhor o Asperger e ajudarmos pessoas que têm esse diagnóstico".

Em seguida foi proposta a primeira tarefa da pesquisa que teve como mote disparador a pergunta: "Como é ter TA?". Para tanto, foi proposto o uso adaptado da técnica de Instrução ao sósia - proposta inicialmente pela Clínica da Atividade (Clot, 2010). Considerada simultaneamente como instrumento de pesquisa e intervenção clínica, acredita-se que essa técnica se constitui em facilitador de insight para os indivíduos participantes, auxiliando a reflexão sobre a experiência vivida e tendo o potencial de transformá-la. A adaptação da técnica consistiu em solicitar aos participantes que construíssem uma narrativa sobre a vivência do TA para o personagem $\underline{\mathrm{Oh}}$, do filme "Cada um na sua casa", da empresa Dreamworks.

Foi projetada a cena inicial do filme, no qual o personagem vem de outro planeta habitar a Terra e precisa conviver com seres humanos. Para tanto, ele recebe um panfleto que funciona como "manual de instruções" sobre os humanos, mas que contém pouquíssimas informações. A seguir foi dada a seguinte instrução:

"Oh é um ser de outro planeta que veio habitar a terra. Como vimos no vídeo, ele é um Boov, e todos os boovs receberam um panfleto sobre como a Terra funciona. No filme, nós vemos que o Oh está começando a aprender sobre muitas coisas e, agora, está particularmente interessado em aprender sobre as pessoas desse planeta, mas, como vimos, ele percebeu que nem tudo está no panfleto e as pessoas parecem mais complicadas do que diz lá. Uma coisa que ele descobriu é que existem pessoas que têm Transtorno de Asperger, mas não achou nada sobre isso no panfleto. Ele acredita que adolescentes ou jovens adultos como você, com TA, são os verdadeiros experts que podem ensinar as outras pessoas sobre como é ter TA. Ele gostaria de entender sobre como é ter TA, como isso te afeta e como faz você se sentir, bem como que impactos do TA você percebe no seu dia a dia.

Ao final da narrativa, foram feitas perguntas objetivando interagir e compreender de forma mais aprofundada as dimensões específicas de suas experiências e conhecimentos acerca do TA. 


\section{Resultados}

\section{L., 20 anos, sexo masculino, estudante de tecnologia da informação}

A produção narrativa de L., elaborada a partir das tarefas anteriormente descritas, é iniciada com afirmação que ilustra a circunscrição do seu entendimento sobre o TA ao domínio conceitual, destacando a necessidade de busca de documentos científicos para respaldar a sua resposta à questão inicial:

L.: "Bem...eu não cheguei a pesquisar exatamente o que que é um TA... ainda vou procurar um pouco mais sobre isso pra se entender um pouco melhor e poder tentar ser igual às outras pessoas”.

Adicionalmente, L. faz referência a um conjunto de conhecimentos acerca do TA adquiridos em literatura e programas de mídia. Esses parecem auxiliá-lo na descrição do TA e no reconhecimento de algumas características desse nele próprio, principalmente relacionadas a experiências de outros indivíduos diagnosticados com TA. Ele informa, em sua fala, conhecer o filme de Temple Grandin e o livro de John Elder Robinson:

L.: "eu conheço uma pessoa que tem autismo que até teve o filme...acho que já te disse esse filme...da Temple Grandin... Um livro! Olhe nos meus olhos".

Complementa que são adultos com TA, e que esses o ajudaram a identificar características do transtorno em si mesmo. Isso pode ser percebido quando ele menciona o livro de Robinson:

L.: "o mesmo padrão do caminhão que ele tinha eu identifiquei com o lego...o avião que eu montava quando era criança e também com os dragões que eu normalmente desenhava do mesmo jeito."

Posteriormente, L. também destaca o papel dos pais na compreensão do TA, e esse é justificado, mais uma vez, não em vivências, mas em pesquisas, leituras e conhecimento científico:

L.: porque já pesquisaram sobre isso e às vezes eles me ajudam a me orientar pra não parecer que eu tô com essa... pra não ficar parecendo que eu estou com essa síndrome ... e ... ajudem seus filhos a se portarem...que encontre meio delas contornarem seus problemas sem causar muito transt...muito ...sem que elas tenham que passar por transtornos.

Ou tro aspecto salutar refere-se à sobreposição das vozes de L. e do seu pai ao apontarem pontos de força e fragilidade que caracterizam o TA. Para L. as maiores dificuldades são aquelas encontradas no domínio da interação social:

L.: em algumas vezes eu não consigo me relacionar direito socialmente... o minimo que seja... e quando eu vou conversar com alguma pessoa, às vezes eu não... eu tenho que terminar o conteúdo que eu tô dizendo pra deixar ele falar.

De forma semelhante, para o pai de L. as maiores dificuldades enfrentadas por ele também estão no âmbito da interação social:

Pai L.: Ah o que atrapalha mais o dia a dia éo relacionamento social...é formar e integrar grupos sociais. Você percebe que se você tá parado e você se intromete em assuntos que 
estão sendo conversados em determinado grupo, normalmente ele não aceita bem essas intromissões... Ainda o entristece a parte social. Isso aí é notório.

No tocante aos seus pontos de força, L. e seu pai insistem na importância da inteligência superior à média (identificada em L. desde a infância) e, simultaneamente, na habilidade em fazer uso dessa como estratégia de superação das dificuldades sociais enfrentadas. Essa ideia está presente no discurso do pai no trecho em que este relata uma conversa com L. na qual explica o diagnóstico do filho:

Pai L.: O Asperger é um espectro do autismo

\section{L.: Mas porque que ele parece um deficiente?}

Pai L.: Porque é um espectro no qual você vai ter dificuldade só no lado social, mas você não tem dificuldade cognitiva.

L.: Se eu não tenho dificuldade cognitiva, porque que minha cognição não é igual a de outra pessoa, é maior?

Pai L.: É porque, por sorte sua, puramente por sorte, a sua área social, se ficou algo inibida, houve uma compensação a mais na área cognitiva.

No discurso de L. a referência à capacidade intelectual acima da média pode ser identificada na seguinte afirmação:

L.: "o TA é mais uma um tipo de su...pra mim o TA não é uma mera deficiência em si, é mais uma superdotação e uma pequena ligeira dificuldade de se relacionar com as pessoas...se a pessoa for um pouco tímida".

Por fim, ambos defendem que as características do TA devem ser "escondidas", que a imitação do comportamento dos outros é igualmente uma rota alternativa de minimização das fragilidades. Ao ser questionado acerca de uma dica para alguém com TA, L. afirma:

L.: Na verdade eu daria algumas dicas de como se portar na sociedade, algumas coisas que eles têm, tiraria algumas dúvidas que eles têm sobre se comportar na sociedade e diria pra eles pra que não precisasse de...ficar contando isso pra...não precisa contar sobre essa doença pra todo mundo e pra se...pra tentar fazer com que as pessoas não percebam que você tem essa dificuldade e seja uma pessoa que tente se parecer com as outras pessoas, mesmo que você não seja igual a eles.

Para o pai de L. sempre esteve claro que a orientação a dar a L. era de disfarce de suas peculiaridades:

Pai L.: oh, tente imitar mais as expressões, cuidado quando as pessoas ficarem tal... ... ah, pra você se misturar às pessoas tente agir como elas. Então assim, por exemplo, alguém sentava, cruzava a perna tal, então ele ia, olhava e ficava do mesmo jeito. 


\section{R., 20 anos, estudante de graduação em engenharia de alimentos}

A produção narrativa de R. para a questão disparadora acerca de como é ser Asperger é fortemente marcada pela presença da opinião de sua mãe. Ele convoca constantemente as suas concepções e representações sobre o TA, com destaque para a relativa tranquilidade diante do diagnóstico:

R.: no início eu não dei tanto valor a esse assunto. Quando eu soube que era só um espectro autista, minha mãe ficou mais aliviada por saber que era apenas o grau mais leve de autismo... Num fico triste com isso não. Também eu não fico feliz. Mas eu me sinto bem, eu tô tentando vencer minhas limitações.

De forma similar, a mãe de R. demonstra aceitação e tranquilidade diante do diagnóstico: Mãe R.: "não, não mudou, eu vendo assim desde pequeno até hoje, é como se ele: 'descobriu? Pronto, meu problema é esse'. Mas era algo que ele sempre fez, ele só sabe que tem certos limites e pronto".

Outro aspecto peculiar da narrativa de R. é o apoio nas falas e histórias de vida de outros sujeitos com diagnósticos diversos na tentativa de caracterizar as suas experiências, tal como identificado no trecho em que descreve como é ter TA:

R.: eu até já tinha pensado nisso também porque por mais que a pessoa tenha entendimento do que é miopia, dislexia, ou qualquer outra coisa, só a pessoa que realmente tem é que pode explicar. Por exemplo, eh...tem na internet como uma pessoa míope vê... a visão normal e a visão míope...só quem tem a visão míope realmente sabe como é, que é o meu caso.

Ressalta-se que, apesar dessa introdução sugerir que ele teria reflexões acerca dessas vivências, ele não aprofundou as reflexões, circunscrevendo a sua produção narrativa a aspectos de ordem teórica e, mais uma vez, apoiando-se na experiência de outros, na fala de outros, aqui no caso, a experiência de um amigo seu de universidade com o diagnóstico de dislexia.

Nas produções narrativas de R. também é possível identificar a presença de elementos comumente difundidos na mídia em termos do TA. Nesse sentido, é marcante sua associação do diagnóstico à ideia de "gênio", bem como a pessoas famosas e bem-sucedidas. Essa associação, que é comum na mídia, parece influenciar inclusive a foma como ele se sente em relação ao TA. Isso pode ser inferido a partir do seguinte trecho:

R.: mas assim sinceramente eu não me envergonho de ter TA, até porque um dos maiores gênios da humanidade, que já ganhou o prêmio Nobel de física e desenvolveu as leis de Newton, esses dois cientistas tinham o TA. Inclusive um jogador de futebol muito famoso, o Messi, que é considerado um dos melhores do mundo e foi considerado o melhor jogador.

Por fim, destacam-se as estratégias de enfretamento do TA, notadamente em termos das dificuldades na interação social. De forma diferente daquela utilizada por L. e seu pais, R. e sua mãe destacam a importância de explicar socialmente o TA e o quanto tal posicionamento traz benefícios. A mãe, ao se colocar no lugar do filho e ensaiar produzir uma narrativa que poderia ter sido enunciada por ele, produz o seguinte relato para as maiores dificuldades enfrentadas: 
Mãe R.: eu falo tudo isso, e às vezes as pessoas não me entendem...o porquê de eu agir assim... e mainha fica explicando porque eu tenho essa sindrome que tem que todo mundo entender, ter paciência comigo. E às vezes eu fico chateado com o almoço familiar. Fico bem chateado mesmo, medo de falar. Me altero e mainha: tenha paciência meu filho, tenha paciência, até eu me acalmar, mas outro dia que eu encontrar aquele fulano, aí eu vou de novo questionar aquilo, daquela pergunta que ele me fez naquele dia, aí vou perguntar pra ele se ele: você não entende não assim, que eu sou assim, até que o fulano fique mais assim: não tudo bem, não tem problema não.

R. ao se referir às dificuldades de socialização relata o quanto elas melhoraram após comunicar aos colegas sobre o TA:

R.: "é...alguns dos meus colegas...eles sabem que eu tenho TA e eles me entendem e assim, hoje em dia eu ainda me isolo, mas não é com tanta frequência”.

\section{W., 16 anos, estudante do $3^{\circ}$ ano do ensino médio}

De modo similar ao que foi identificado nas produções narrativas anteriores, no caso de W. identifica-se semelhança entre as suas representações e de seus pais acerca do TA. Entretanto, para ambos o diagnóstico e a experiência deste em suas vidas vem revestido de grande sofrimento, em especial decorrente da comorbidade com o transtorno obsessivo compulsivo (TOC), conforme explicitado no seguinte trecho produzido por W:

W.: porque o Asperger ele é meio que um empecilho na minha vida...ele é meio que um transtorno que afeta as minhas relações sociais e até mesmo minhas dificuldades na vida vêm desse transtorno que pode gerar outros transtornos como o TOC ... bem, já que a $S A$ me fez ter TOC, então não me sinto muito bem com isso não. Me fez desenvolver TOC, porque...eu sou mais propício a desenvolver TOC, porque eu sou hipersensivel às coisas que me apresentam.

De forma similar a mãe afirma:

Mãe W. : "Eu acredito, na minha concepção, que todo o problema gira em torno do TOC, entendeu? Porque se ele fosse um Asperger puro ele era muito tranquilo...tranquilo demais".

W. recorre em seu discurso principalmente a aspectos conceituais relativos à literatura médico-científica para caracterizar o TA. Ele enumera critérios nosológicos, a exemplo do trecho:

W. : falta de entendimento dos procedimentos sociais, não saber como levar uma conversa adiante, não entender sarcasmo...não entender as...não entender ironia... Dificuldade de julgar ações e de identificar o sarcasmo, a intenção da pessoa. Eu também tenho...e também dificuldade de contato visual.

No entanto, também se identificam elementos em sua fala que advêm de informações midiáticas, como a associação do diagnóstico a gênios, pessoas famosas e bem-sucedidas como Albert Einstein, cientista, ou Lionel Messi, jogador de futebol: 
W. : "mas eu posso dizer que eu sei quem tem, porque eu já ouvi falar que aquelas pessoas tinham. Einstein, por exemplo, tinha (...) Messi também tem. Messi, jogador de futebol. Tem Asperger".

Ele ainda relata ter sido por meio da mídia que entrou pela primeira vez em contato com o diagnóstico de TA, tendo se identificado com Satoshi Tajiri, criador do jogo Pokemón, do qual era fã:

W. : "Ah eu era pequeno ainda [respondendo a pergunta sobre quando descobriu que tinha [TA] ...eu descobri que Satoshi Tajiri que foi um japonês que criou Pokémon ele tinha AS... Ele foi diagnosticado".

Este supostamente teria o diagnóstico de TA, o que provocou sua curiosidade e trouxe a descoberta desse diagnóstico com o qual se identificou.

Por fim, nota-se mais uma vez a sobreposição das vozes de W. e seus pais na indicação de conselhos para pais de pessoas com TA. W. sugere aos pais que:

W. : Tentem conversar com ele com frequência [seus filhos], tentem dar atenção a ele, porque ele é como um ser humano normal... que eu sei que vocês sempre deram...tentem tratar ele como vocês sempre trataram ele... apesar das dificuldades. Façam o seu filho feliz porque ele pode estar meio infeliz... com o ambiente... exterior.

Por sua vez, a mãe de W. similarmente sugere:

Mãe W.: que desse muito amor a ele. Muito amor, atenção, que lutasse por ele e que conseguisse dar um bom apoio psicológico que eu acho que a coisa melhora. Muito amor, eu acho que eles precisam muito disso. Amor, atenção e um acompanhamento psicológico adequado. Que é o que a gente busca fazer, sempre.

\section{Discussão}

O presente estudo teve como objetivo maior ampliar a compreensão acerca dos processos de insight no TA. Para tanto, faz-se necessário tecer considerações acerca do desenvolvimento ontogenético, aqui compreendido enquanto movimento dialógico, no qual as funções psicológicas têm substrato na corporeidade, mas são igualmente interdependentes dos contextos emocionais e socioculturais nos quais o sujeito está imerso. Isso posto, assume-se aqui a centralidade do sujeito enquanto agente autônomo, imerso num mundo organizado culturalmente. Porém, é preciso ressaltar que a autonomia pessoal e a individuação são, elas próprias, culturalmente constituídas, através do processo de internalização/externalização (Budwig, Valsiner, \& Bamberg, 1998; Hughes, J., 2019).

Com base nessas premissas propõe-se aqui a aproximação de dois lugares teóricos distintos, mas potencialmente complementares, a saber, a psicologia histórico-cultural e a filosofia da linguagem do Círculo Bakhtin. Ambas compartilham a perspectiva de construção social da mente e a natureza objetiva da linguagem, interessados na dimensão da construção de sentido da vida humana, em especial, aquelas manifestações da vida psíquica que podem ser expressas através de narrativas (Cornejo, 2012). 
A dialogia e a presença do "outro" são essenciais na constituição da subjetividade, possibilitando contradições que, ao criarem tensões e conflitos, promovem a produção de novos significados (Magalhães \& Oliveira, 2011).

Para Bakhtin, a consciência individual constrói-se na interação sujeito-mundo social. O sujeito tem papel ativo na sua construção, não sendo assujeitado, mas relacional, se torna eu entre outros eus: ao mesmo tempo é definido por um outro e define este, de tal forma que se tem uma concepção inacabada de sujeito, sempre em ressonância no outro, no discurso do outro e nos interdiscursos, compreendidos pelas vozes sociais que ecoam, trazendo-lhes um caráter histórico e cultural (Brait, 2005).

Para Vygotsky, a emergência das funções mentais superiores é dada nas relações sociais, mas esta não ocorre de forma direta, é mediada por instrumentos ou signos. Nesse processo, a linguagem ganha papel de destaque, pois fornecerá os elementos decisivos para que os processos psicológicos inferiores, inicialmente independentes (funcionamento unimodal), sejam integrados, constituindo redes complexas capazes de produzir significados (funcionamento polimodal). Tal processo desenvolvimental possibilitará a emergência da consciência. Essa integração ocorre à medida que os significados culturais são apropriados, primeiro interpsicologicamente, na relação com o outro, para tornaremse intrapsicológicos, internalizados (Vygotski, 2012).

Nessa apropriação, na qual M. Bakhtin (1981) defende a centralidade do diálogo, existem diferenças entre o que é falado e o que é ouvido que leva a entendimentos diferentes para cada participante do processo, existindo necessariamente uma lacuna entre os indivíduos. Bakhtin sugere que é nessa lacuna que emergem novas ideias sobre o mundo e sobre si mesmo e é onde se constroem as vozes individuais. Na relação entre pais e filhos, esse intervalo permite o desenvolvimento destes e formação de identidade a partir da coconstrução dialógica de sentidos sobre si mesmos.

Nesse sentido, diversos estudos sugerem o papel das crenças e discursos dos pais acerca das habilidades dos filhos, principalmente em relação a aspectos acadêmicos, nas crenças destes acerca deles mesmos (Frome \& Eccles, 1998). No presente estudo busca-se explorar a relação entre os discursos de pais e filhos e a influência do discurso dos primeiros na percepção acerca do diagnóstico dos segundos, contribuindo para a constituição de sua identidade.

Salienta-se aqui a perspectiva de M. Bakhtin (1981) acerca do desenvolvimento da identidade no contexto social compartilhado, permeado de vozes e discursos. Nessa constituição, distinguem-se dois tipos de discursos dialógicos que atuam nas vozes individuais. O primeiro é uma forma de discurso externalizada em que o discurso em desenvolvimento da criança reflete uma aliança incondicional com a voz da autoridade. Isso é caracterizado por repetição mecânica de frases ou narrativas que não foram totalmente internalizadas e apropriadas como deles mesmos. No segundo, mais avançado, a criança se engaja no diálogo interno persuasivo. Aqui, a voz dos outros não só é audível no discurso da pessoa, mas foi assimilada e reconstruída (Tappan, 2005). Do ponto de vista de pais e filhos, a voz dos pais é constitutiva do discurso inicial de autoridade, cujos elementos são internalizados pelo filho que irá, posteriormente, clamar autoridade e responsabilidade pela fala, apesar de essa ser uma resposta à visão dos pais da forma como o filho as compreende e reconstrói. 
Outro conceito central na teoria de Bakthin, e aqui de especial relevância, é o de exotopia. A exotopia se cria quando, provido do olhar do outro, retorno a mim mesmo e efetivamente coloco em ação o excedente de visão que o outro me proporcionou, promovendo mudanças internas e, consequentemente, promovendo a emergência da novidade, o que, por sua vez, caracteriza o processo de desenvolvimento (Bakhtin, 1981). Porém, esse processo não acontece obrigatoriamente. Para que ele ocorra é necessário o esforço de posicionarse a partir do ponto de vista do outro, buscando ver o que o outro vê. Quando o indivíduo se perde nesse movimento, apenas refletindo um ponto de vista, existe uma captura desse olhar que não leva necessariamente à mudança e expansão de consciência (Wesling, 2016).

A centralidade da linguagem para o desenvolvimento das funções psicológicas superiores exige a reflexão acerca de comprometimentos neste domínio para a constituição do sujeito. No caso do TA é imprescindível problematizar sobre o perfil das alterações nesse domínio e as implicações desse para o desenvolvimento. Isto porque a consciência não se utiliza da língua como quem mobiliza um conjunto de regras normativas, este sistema formal é na verdade uma abstração. Sendo assim, não se pode negligenciar que o sujeito mobiliza e usa a língua em situações concretas. Assim, a relevante dimensão desse processo não está no formal, mas no novo significado produzido nesse contexto. Ou seja, a forma linguística ganha importância no momento em que se apresenta como signo flexível e variável, não como sinal estável (Volochinov, 1992).

De tudo o que foi dito decorre que, se a língua só ganha relevância na sua dimensão de variabilidade e flexibilidade, o foco de investigação deve deslocar-se do que está em conformidade com a dita norma para a novidade que emerge. A palavra é, na verdade, uma orientação que é a esta conferida por um contex to e uma situação específicos. É interessante notar que no universo Asperger o signo linguístico perde exatamente essa dimensão de flexibilidade e novidade. O processo fica estanque na dimensão do significado da palavra, não do sentido que a palavra ganha naquele contexto singular. Salienta-se que participam da construção desse sentido dimensões da linguagem não veiculadas através da fala, tais como expressões faciais, comportamentos, condições sociais; este conjunto de enunciados confere àquele contexto uma dimensão única, mas para o Asperger ela costuma estar aprisionada num mesmo significado, imutável e rígido.

Nesta perspectiva a característica central do funcionamento Asperger pode ser descrita como uma disrupção na transição de um modo monológico para um dialógico de pensamento, comprometendo o engajamento na relação com os pares. O Asperger apresenta dificuldades para desenvolver uma narrativa própria, para acrescentar novidade ao entrelaçamento com os seus pares. Por vezes, seu discurso parece apenas refletir e repetir, ecoar as vozes sociais. Nesse sentido, a produção de significados e sentidos tende mais a reproduzir as concepções da sociedade.

Sendo as vozes da cultura aquelas entoadas pelos sujeitos Asperger, as suas identidades e consciências, qualitativamente diversas, vão denunciar os preconceitos e dificuldades nas relações da sociedade com as condições destoantes. O modelo biomédico converte-se na fala dos sujeitos deste estudo, mesclado com os discursos da mídia e dos pais.

Possivelmente a principal característica dos processos de insight para o TA é a manutenção de um discurso monológico, sem a presença constante da novidade, na ausência da autenticidade. Convém então questionar se se trata de ausência de insight ou de um modo idiossincrático de produzi-lo. 
Buscando responder à questão acima lançada convocam-se os conceitos de disontogênese e de desenvolvimento heterocrônico (Anokhin, 1975; Vygotski, 2012), que compõem a defectologia vygotskiana, sendo esta contraponto à visão tradicional do sujeito com alterações desenvolvimentais. Para esta última, o desenvolvimento é um processo "natural" de crescimento acumulativo-quantitativo e embasado no incremento das funções psicológicas e orgânicas que já estão predeterminadas pelo biológico.

Tal concepção traduz-se numa visão do sujeito com dificuldades como um ser menos desenvolvido, caracterizado pela falta. Abordar a deficiência sob a ótica da limitação imposta pela condição significa considerar a pessoa com deficiência um simples conjunto de funções negativas, resultando em uma abordagem limitada (Gindis, 1999; Vygotski, 2012). Em contraposição a essa perspectiva, a defectologia vygotskiana baseia-se em uma concepção de desenvolvimento como processo essencialmente qualitativo, de forma que podemos pensar a produção de insight no Asperger não como menos desenvolvida do que outras, mas detentora de um processo desenvolvimental que ocorre de maneira qualitativamente distinta daquela dita normal.

Na defectologia vygotskiana o papel do "defeito" é sempre duplo, pois configura contexto de disontogênese, ou desvio da função típica do desenvolvimento, produzindo falhas, obstáculos e dificuldades na adaptação do sujeito; mas, por outro lado, exatamente porque o defeito produz obstáculos e rompe o equilíbrio normal, ele serve de estímulo ao desenvolvimento de caminhos alternativos e indiretos de adaptação, os quais substituem ou se superpõem a funções que buscam compensar a deficiência e conduzir todo o sistema a uma nova ordem (Vygotski, 2012).

Nessa perspectiva, a dimensão sociocultural é dialeticamente o gérmen da deficiência e o caminho compensatório, pois onde se identifica a limitação biológica, abre-se um caminho, sem limites, para o desenvolvimento cultural. Sendo assim, pode-se concluir que os processos de insight e o desenvolvimento da consciência do Asperger seguem caminhos distintos de desenvolvimento. O entendimento dessas rotas alternativas de desenvolvimento das funções psicológicas superiores, bem como as proposições de intervenções que favorecem tal processo, transformam o negativo da deficiência no positivo da compensação (Vygotski, 2012).

\section{Conclusões}

Estudos diversos têm examinado a percepção e o entendimento que os indivíduos com Transtorno de Asperger têm acerca do mundo e de outras pessoas, porém menos interesse tem sido direcionado para o entendimento desses sobre sua própria condição. Ao mesmo tempo, o conhecimento científico acerca dos comportamentos associados ao TA, suas relações sociais, educacionais e laborais, foi construído a partir do relato de terceiros: relatos de clínicos, pesquisadores e pessoas próximas. Tais relatos constituíram importante fonte de conhecimento sobre o TA no sentido de compreensão de aspectos nosológicos e nosográficos do diagnóstico, bem como de comportamentos observáveis. Para além disso, construíram igualmente uma visão social do diagnóstico pautada nessa percepção externa. 
O presente estudo buscou investigar aspectos relativos aos processos de insight de indivíduos com Transtorno de Asperger acerca de seu diagnóstico. Para tanto, foram confrontadas as suas percepções sobre o TA, as percepções de seus pais sobre o mesmo tema e as contribuições científicas e da mídia. Observou-se que os discursos dos filhos possuem aproximações com as falas dos pais em diversos aspectos, sugerindo a influência desses na constituição da autopercepção de seus filhos.

No que concerne aos limites, ressalta-se que este estudo considerou apenas aspectos relativos à percepção do diagnóstico, sendo necessários estudos que ampliem a compreensão da constituição desse discurso considerando outros aspectos da consciência de si. Ademais, cabe investigar o papel de outras fontes de influência nesse discurso, como professores e profissionais de saúde que acompanham esses indivíduos. Sugere-se ainda a ampliação de estudos de insight com indivíduos diagnosticados com outros transtornos do neurodesenvolvimento como o transtorno de déficit de atenção e hiperatividade, transtornos de aprendizagem e do desenvolvimento intelectual, no intuito de investigar como se constituem os processos de insight nesses diagnósticos, considerando semelhanças e distanciamentos do TA.

Por fim, destaca-se o papel de estudos com narrativas, autobiografias e autorrelatos de indivíduos do espectro do autismo na contribuição para a evolução social e cultural em andamento desse diagnóstico, não só para a sociedade, mas com efeitos transformativos significativos nas experiências do dia a dia dos próprios indivíduos autistas. Tais efeitos decorrem da possibilidade de que, a partir dos exemplos similares, outros indivíduos autistas possam se engajar e explorar suas próprias experiências, mudando também a forma como pensam e falam de si mesmos. Compreender esses aspectos da consciência de si significa compreender a singularidade e eventicidade da existência e da experiência subjetiva. Tais aspectos são essenciais para a real compreensão do que significa se desenvolver de maneira fundamentalmente diferente, sem reduzir o indivíduo a estereótipos sociais, ou achados científicos teóricos, como alterações cognitivas e comportamentos desviantes. 


\section{Referências}

Anokhin, P. (1975). Essays on the physiology of functional systems. Moscow: Medidna. Associação Americana de Psiquiatria - APA. (2014). Manual Diagnóstico e Estatístico de Transtornos Mentais (5 ${ }^{\mathrm{a}} \mathrm{ed}$.). Porto Alegre: Artmed.

Bakhtin, M. (1981). Marxismo e Filosofia da Linguagem. Rio de Janeiro: Hucitec.

Brait, B. (2005). Bakhtin: conceitos-chave. São Paulo: Contexto.

Buchman-Wildlbaum, T., Váradli, E., Schmelowszky, Á., Griffiths, M., Demetrovies, Z., \& Urbán, R. (2020). The paradoxical role of insight in mental illness: The experience of stigma and shame in schizophrenia, mood disorders, and anxiety disorders. Archives of Psychiatric Nursing. https://doi.org/10.1016/j.apnu.2020.07.009

Budwig, N., Valsimer, J., \& Bamberg, M. (1998). Situating Rogoff: The inter-disciplinary study of human development. Clark Working Papers on Developmental Psychology, 1, 1-16.

Clot, Y. (2010). Trabalho e poder de agir. Belo Horizonte: Fabrefactum.

Clot,Y. (2014). Vygotski: a consciência como relação. Psicologia \& Sociedade, 26(2), 124-139.

Cornejo, C. (2012). Contrasting Vygotsky's and Bakhtin's approaches to consciousness. Culture \& Psychology, 18(1), 109-120.

Didehbani N., Shad, U., Kandalaft, R., Allen,T., Tamminga, A., Krawczyk, C., \& Chapman, B. (2012). Brief Report: Insight into Illness and Social Attributional Style in Asperger's Syndrome. Journal of Autism and Developmental Disorders, 42(12), 2754-2760.

França, G., Laranjeira, E., Silva, F., Monteiro, L., Moreira A. M., \& Carvalho, S. (2020). Attachment Style and Insight in Schizophrenia: A Cross-Sectional Study. Psychiatr Q, 91, 31 43. https://doi.org/10.1007/s11126-019-09675-8

Frome, P. M. \& Eccles, J. S. ? (1998). S. Parents' influence on children's achievement-related perceptions. Journal of personality and social psychology, 74(2), 435-452.

Gindis, B. (1999). Vygotsky's Vision. Remedial and Special Education, 20(6), 333-340.

Langdon, R., Cormer, T., McLaren, J., Ward, P., \& Coltheart, M. (2006).. Externalizing and personalizing biases in persecutory delusions: The relationship with poor insight and theory-ofmind. Behaviour Research and Therapy, 44(5), 699-713.

Hughes, J. (2019). Insight: The concept, the assessment and the label. BJPsych Advances, 25(2), 131-132. https://doi.org/10.1192/bja.2018.58

Magalhães, C. \& Oliveira, W.(2011). Vygotsky e Bakhtin/ Volochinov: dialogia e alteridade. Bakhtiniana. Revista de Estudos do Discurso, 1(5), 103-115.

Marková, I. (2005). Insight in psychiatry. Cambridge: Cambridge University Press.

Markova, I. \& Berrios, G. (2011). Awareness and insight in psychopathology: An essential distinction? Theory \& Psychology, 21(4), 421-437.

Organização Mundial da Saúde - OMS. (1996). Classificação Estatística Internacional de Doenças e Problemas Relacionados à Saúde: CID-10 Décima revisão. Trad. do Centro Colaborador da OMS para a Classificação de Doenças em Português ( 3a ed.). São Paulo: EDUSP. Schriber, R., Robins, R., \& Solomon, M. (2014). Personality and self-insight in individuals with autism spectrum disorder. Journal of Personality and Social Psychology,106(1),112-130. Tappan, M.(2005). Domination, Subordination and the Dialogical Self: Identity Development and the Politics of "Ideological Becoming". Culture \& Psychology, 11(1), 47-75.

Verhoeven, E., Marijnissen, N., Berger, H., Oudshoorn, J., van der Sijde, A., \& Teunisse, J. (2012). Brief Report: Relationship Between Self-Awareness of Real-World Behavior and Treatment Outcome in Autism Spectrum Disorders. Journal of Autism and Developmental Disorders, 42(5), 889-894. 
Veresov, Nilkolai (2014). Method, methodology and methodological thinking. In M. Fleer \& A. Ridgway (Eds.), Visual Methodologies and Digital Tools for Researching with Young Children (pp. 215-228). Meulborn: Springer, 10.1007/978-3-319-01469-2_12.

Vygotski, L. (2012). Obras escogidas V: Fundamentos de defectología. Madrid: Antonio Machado Libros.

Volochinov, V. (1992). Marxismo e filosofia da linguagem. São Paulo: Hucitec.

Wesling, D (2016). Bakhtin, Pushkin, and the Co-Creativity of Those Who Understand. Bakhtiniana, São Paulo, 11(3), 202-215.

\section{CAROLINA VILAR \\ https://orcid.org/0000-0002-8509-2412 \\ Mestrado. Universidade Federal do Rio Grande do Norte. \\ E-mail: carolinabvilar@gmail.com}

\section{AMANDA GUERRA}

https://orcid.org/0000-0003-2320-8771

Mestrado. Universidade Federal do Rio Grande do Norte e

Université d'Angers.

E-mail: adlbguerra@hotmail.com

\section{JORGE FALCÃO \\ http://orcid.org/0000-0002-2798-3727}

Estágio pós-doutoral. Departamento de Psicologia, Universidade Federal do Rio Grande do Norte.

E-mail: falcao.jorge@gmail.com

\section{IZABEL HAZIN \\ http://orcid.org/0000-0002-4045-8628}

Estágio pós-doutoral. Departamento de Psicologia, Universidade Federal do Rio Grande do Norte.

E-mail: izabel.hazin@gmail.com 


\begin{tabular}{|c|c|}
\hline Histórico & $\begin{array}{l}\text { Submissão: 08/06/2018 } \\
\text { Revisão: 29/09/2020 } \\
\text { Aceite: } 17 / 08 / 2020 \\
\end{array}$ \\
\hline Contribuição dos autores & $\begin{array}{l}\text { Concepção: CV e IH } \\
\text { Coleta de dados: CV } \\
\text { Análise de dados: CV } \\
\text { Elaboração do manuscrito: CV, IH AG e JF } \\
\text { Revisões de conteúdo intelectual importante: IH; JF } \\
\text { Aprovação final do manuscrito: CV e AG }\end{array}$ \\
\hline Consentimento de uso de imagem & Não se aplica. \\
\hline Aprovação, ética e consentimento & $\begin{array}{l}\text { A execução do projeto foi aprovada pelo Comitê de } \\
\text { Ética em Pesquisa da Universidade Federal do Rio } \\
\text { Grande do Nortre (CEP-UFRN) sob o códifgo CAAE } \\
51838515.5 .0000 .5537 .\end{array}$ \\
\hline Financiamento & $\begin{array}{l}\text { Bolsista de Produtividade do CNPq - Nível } 2 \text { - IH } \\
\text { Bolsista nível mestrado da CAPES - CV (149162 1) } \\
\text { Bolsista nível doutorado da CAPES - AG (1654284 e } \\
\text { 88881.189733/2018-01) }\end{array}$ \\
\hline
\end{tabular}

